\title{
DINAMIKA KEPRIBADIAN DALAM PRESPEKIF PSIKOLOGI ISLAM: TELAAH KRITIS PEMIKIRAN IMAM AL - GHOZALIE
}

\author{
Fikiy Afriyanto \\ UIN Sunan Ampel Surabaya \\ Afry.fiki@mail.com \\ Abdul Muhid \\ UIN Sunan Ampel Surabaya \\ abdulmuhid@uinsby.ac.id
}

\begin{abstract}
Abstrak
Kepribadian adalah bagian dari ruh yang membentuk kehidupan manusia menjadi satu kesatuan, tidak terpisahkan kapasitasnya. Memahami kepribadian menyiratkan pemahaman mengena diri sendiri, atau pemahaman individu secara total. Sigmunnd Freud menjelaskan bahwa ada tiga komponen dalam konstruksi tersebut karakter, khususnya id, citra diri, dan kepribadian super. kepribadian menurut psikologi islam adalah koordinasi pengaturan hati, kecerdasan, dan kepentingan manusia yang mengarah pada perilaku. Sudut nafsani manusia memiliki tiga kekuatan, tepatnya: (1) hati (fitrah ilahiyah)sebagai bagian dari supra-kesadaran manusia yang memiliki kekuatan nafsu (perasaan); (2) penilaian yang baik (fitrah insaniah) sebagai bagian dari kesadaran manusia yang memiliki kekuatan psikologis(membuat); (3) keinginan (fitrah hayawaniyah) sebagai bagian dari pra atau kejelasanorang yang memiliki kekuatan konasi (tujuan). Elemen karakter ke dalam Ada tiga sudut pandang Islam, yaitu kepribadian ammarah (nafsal-ammarah), kepribadian lawwamah (nafsal-lawwamah), ahlak muthmainnah(nafsalmuthmainnah). Gagasan tentang budi pekerti yang diindikasikan oleh pertimbangan al-Ghazali, misalnya,naluri manusia, dorongan dan perasaan, konstruksi roh, tipologi karakteristik manusia, dan teknik peningkatan Moral (mengarahkan). Dari keseluruhan gagasan tentang kepribadian al-Ghazali, hal tersebut menjadi pertimbangan lengkap oleh seorang pemandu dengan tujuan agar hasil konsultasi yang paling ekstrem menjadi mendalam pemanfaatan strategi perbaikan moral seperti strategi taat syariah, teknik kemajuan diri dan teknik untuk kufin.
\end{abstract}

Kata Kunci: Kepribadian; Psikologi Islam; Imam Al - Ghozalie

\begin{abstract}
Character is essential for the soul that shapes human existence into a solitary unit, its ability is indistinguishable. Understanding character suggests getting myself, myself, or a complete comprehension of the person. Sigmund Freud clarified that there are three segments in the development of character, especially the id, mental self portrait, and super character. Character as indicated by Islamic cerebrum science is the coordination of the plan of the heart, knowledge, and human interests that lead to direct. The human nafsani point has three forces, to be exact: (1) the heart (fitrah ilahiyah) as a component of the human supra-cognizance which has the force of desire (feeling); (2) trustworthiness (fitrah insaniah) as a feature of human awareness which has mental ability (to make); (3) want (fitrah hayawaniyah) as a component of the pre or clearness
\end{abstract}


of an individual who has the force of conation (objective). Internal character components There are three Islamic perspectives, in particular the personality of ammarah (nafsal-ammarah), ethical quality lawwamah (nafsal-lawwamah), andethical quality muthmainnah (nafsalmuthmainnah). Al Ghazali's concept of character as a supporting suspected in understanding individual characters works with a pattern of bearing. The thoughts of character demonstrated by al-Ghazali's contemplations, for instance, human impulses, drives and sentiments, soul developments, typology of human attributes, and Good Improvement (Coordinating) methods. From the entire thought of al-Ghazali's character, that will be a finished thought by a guide with the point that the consequences of the most limit interviews become inside and out the use of good improvement procedures, for example, sharia-standing methodologies, selfheadway strategies and methods for kufin.

Keywords: Personality; Islamic Psychology; Imam Al - Ghozalie.

\section{Pendahuluan}

Alquran menggambarkan kepribadian manusia dan kualitasnya secara keseluruhan terpisah dan berbeda dengan mahluk lainnya. Alquran juga menyebutkan beberapa contoh terlebih lagi, model kepribadian umum yang normal bagi semua orang.Untuk memahami kepribadian manusia secara tegas dan secara mendalam, kita perlu berkonsentrasi dengan variabel-variabel pembatas kepribadian.(Muhimmatul Hasanah, 2018: 110-122) Peneliti psikologi saat ini mempelajarinya dengan perhatikan dengan hati-hati kecenderungan yang berbeda untuk organik, sosial, dan komponen budaya. Meskipun demikian, mereka mengabaikan penyelidikan jiwa manusia (tengah). terlebih lagi, pengaruhnya terhadap kepribadian.(Andriansahroji, 2019:62-74) Kepribadian tidak mudah untuk dipahami oleh manusia jelas tanpa mengetahui ide ide, semua hal dipertimbangkan, yang membatasi karakter, baik material maupun non material.(Ali Y, 2012:1)

Menurut pengertian umum atau kontemporer, kepribadian dikenal sebagai istilah syakhshiyah yang bisa dikoordinasikan dengan kepribadian. Istilah syakshiyah sendiri tidak pernah ditemukan dalam persepsi islam gaya lama, bagaimanapun caranya samakatanya (bukan berarti serupa) dalam meneliti kepribadian manusia bisa ditemukan sejauh etika. Ada satu hal yang mengenali konsentrasi struktur kepribadian. Penelitian psikologi barat dengan itu dalam Islam, untuk lebih spesifik situasi jiwa. Dalam investigasi di barat, istilah jiwa (atau sesuatu yang sebanding) jarang ditemukan, namun sebenarnya dalam Islam situasi jiwa adalah fundamental. Dalam ungkapan Islam 
struktur karakter seperti dalam hipotesis psikoanalitik, ia dikenal sebagai tubuh, jiwa, dan nafs.(Sudjana Aki, 2016: 91)

Memahami pentingnya menasihati dengan metodologi Islam, khususnya bagi individu penasihat dan konseli yang beragama Islam, di mana persyaratan fundamental orang berada mendapatkan ketenangan hidup. Pelajaran Islam mengandung banyak petunjuk ke dalam semua masalah sehari-hari yang dapat memenuhi persyaratan mendasar ini.(Suparlan, 2012:33) Berawal dari persoalan bagaimana Islam menawarkan pendekatan membantu individu yang mengalami masalah mental yang berbeda di Dalam siklus menasihati, pemateri mengangkat kepribadian seorang analis Islam dalam menggambarkan hipotesis karakter sebagai premis atau alasan pemahaman karakter individu melewati interaksi arah dan membimbing untuk hasil yang ideal adalah AlGhozali yang termasuk di antara sekian banyak tokoh Islam yang ada memenuhi syarat dalam ujian mental, Al-Ghozali-lah yang banyak berbicara tentang gagasan ilmu otak secara mendalam.(Hasanah, 2019:23)

\section{Metode Penelitan}

Metode peenelitian yang digunakan oleh peneliti adalah dengan mengguunakan literaturr review. Penelitian ini menggunakan prosedur subjektif dengan pendekatan kualitatif deskriptif. Teknik subyektif adalah suatu sistem ujian yang menghasilkan informasi yang berbeda berupa kata-kata yang tersusun atau diungkapkan secara verbal dari individu dan perilaku nyata yang ditegakkan dengan studi tulis atau tulisan yang dianggap bergantung pada perluasan survei tulisan sebagai informasi dan angka, sehingga realitas dapat dipersepsikan. (Nurviyanti Cholid, 2018:75)

\section{Pembahasan}

\section{A. Biograi Al - Ghozalie}

Imam Ghozali (1059-1111M) bukanlah peneliti yang asing dengan dunia islam, sebagai seorang ulama Al-Ghozali memiliki banyak predikat, diantaranya rasionalis, spesialis fiqh dan studi kalam, spesialis ilmu otak dan konselor hukum. Selanjutnya di Barat Al-Ghozali dikenal sebagai "Alghazel". Sebagai sosok Al-Ghozali yang luar biasa adalah juru perbaikan Islam di masa-masa baru Al-Ghazali menjadi guru di Madrasah Nizhamiyah di Baghdad, a lembaga pendidikan lanjutan kelas satu pada zamannya. Di tempat yang ditinggikan dan Patut dicatat bahwa dia menemukan perasaan waspada dan 
pertanyaan-pertanyaan di dalam ditarik dengan alasan bahwa dia mengerti bahwa pekerjaan yang dia lakukan sebagai guru tidak tergantung pada tujuan yang benar untuk Allah, tetapi lebih ditentukan oleh keinginanmemperoleh perbedaan dan tempat yang ditinggikan. Begitu pula berbagai ilmu yang telah bertahanIni diinstruksikan.(Khoiriyah Ulfa, 2015:123).

Sejujurnya, seperti yang ditunjukkan olehnya, pendirian itu sangat rumit. Kesulitan menyelesaikan pergulatan batiniah membuatnya dilemahkan dengan manifestasi tidak mampu mengungkapkan kata-kata dan benar-benar kehilangan rasa lapar, sehingga spesialis menawarkan bimbingan kepadanya untuk mengalahkan kondisinya sendiriAkibatnya dia berusaha mengobati penyakitnya sendiri dengan semakin dekat dengan Allah. Akhirnya usahanya membuahkan hasil, dia sembuh dari penderitaan yang dia alami. Dia ternyata lebih pendiam dalam mentalitas dan keuntungannya "Kepastian" tentang sains. Dia meninggalkan semua pemborosan, kekayaan, menghormati kehormatan dan keluarga di Baghdad. Dia pindah ke Damaskus (Damaskus-Syria) pada tahun $484 \mathrm{H}$, dan di kota ini dia merenung, membaca dan menulis, selama sekitar dua tahun, dengan tasawuf sebagai gaya hidupnya.(Anri Saputra, 2019:37).

Pada saat itu dia pindah ke Palestina dan di sini dia terus memikirkan, membaca dengan teliti Selanjutnya, mengaransemen dengan dilakukan di ruang Masjid Baitul Maqdis. Setelah itu tergerak hatinya untuk melakukan perjalanan ke Mekah - Madinah dan sesudahnya selesai dia kembali ke negara pengenalannya pada dunia, kota Karenanya dan disana dia tinggal seperti normal, berlatih dan menghormati. Keadaan saat ini bertahan sepuluh tahun, sejak peralihannya ke Damaskus dan selama waktu itu ia menyusun buku-bukunyaYang terkenal termasuk Ihya Ulum al - Racket.(Muhamad Afifudin Alfarisi, 2015:42). Karena faktor desakan penguasa saat itu, tepatnya Muhammad Saudara Berkijaruk,al-Ghazali perlu dididik kembali di sekolah Nidzamiyah di Naishabur pada tahun 499 H Meskipun demikian, pekerjaan itu hanya bertahan dua tahun, hingga akhirnya dikunjungi kembali Sejalan dengan itu, di mana ia kemudian mendirikan sekolah Fuqaha dan komunitas religius (khankah) untuk mutasawwifin. Setelah berenang di Laut kehidupan yang luar biasa dan terjun ke lautan pengetahuan yang terpencil, dia meninggal di tanah perkenalannya dengan dunia, Taberan pada 14 Jumadil Akhir 505 H selaras dengan tanggal19 Desember $1111 \mathrm{M}$. 
Seperti biasa dengan peneliti tradisional dan orang terpelajar lainnya, pandangan ini Pandangan Imam Ghazali juga mencakup berbagai ilmu yang ada di dalamnya waktu dan mengedepankan aturan logis yang menarik pertimbangan peneliti usia saat ini dan nanti dari spesialis ketat yang menggunakannya sebagai bahan pelajaran.(Muhamad Afifudin Alfarisi, 2015:42)

\section{B. Kepribadian}

Kata pribadi berasal dari bahasa Inggris, khususnya character diambil dari bahasa bahasa yunani adalah "prosopan atau persona" yang menyiratkan kerudung yang biasanya dikenakan sebuah teater. Para penghibur teater berperilaku seperti selimut yang mereka kenakan sampulnya membahas karakteristik karakternya. Demikian ide yang mendasari mendapatkan karakter Adalah perilaku yang muncul dalam iklim sosial, kesan diri sendiri ingin ditangkap oleh iklim.(Faiqatul Husna, 2018:112) Karakter manusia sangat beragam, mungkin dengan individu yang tak terhitung jumlahnya, sekelompok spesialis berusaha untuk memesan orang orang memiliki tempat dengan jenis tertentu, karena mereka bersaing karena cara itu metode terbaik untuk berkenalan dengan individu dengan baik. Kemudian lagi sekelompok ahli berpendapat bahwa metode berfungsi seperti yang diungkapkan di atas tidak memenuhi tujuan mental karakter, yaitu untuk memahami apa itu individu individukehadiran, sesuai atribut khususnya; Mengingat fakta bahwa dengan mengkarakterisasi ke dalam tipe-tipe individu benar-benar menyembunyikan keunggulan kualitas seseorang.(Walsh, R., \& Vaughan, F, 2020:22) Ada beberapa istilah yang dianggap setara dengan kata kepribadian Pada titik ketika istilah tersebut digunakan dalam hipotesis kepribadian itu diberikan berbagai implikasi.Istilah-istilah tersebut meliputi:

1. (kepribadian) menggambarkan perilaku secara grafis tanpa memberi ujian (devaluatif)

2. kepribadian menggambarkan perilaku dengan menampilkan nilai (palsu, valid, mengerikan hebat) dengan tegas atau pasti.

3. kepribadian (tata krama) yang telah dimiliki sampai saat ini.

4. Tempramen adalah karakter yang secara tegas diidentikkan dengan sains atau fisiologiterlebih lagi, aura keturunan. 
5. Kecenderungan reaksi yang serupa secara umum akan mengulangi hal yang sama ke dorongan yang sama terlalu.

6. Etika diambil dari metode bahasa Arab.(Zilbersheid, 2019:73)

Alih-alih hipotesis karakter yang dibuat di dunia barat, Imam Al Ghazali secara teratur menggunakan istilah kualitas etika sebagai bagian dari hipotesis karakternya dan melalui pendekatan tasawuf mencoba mengungkap sifat dan tingkah laku manusia melalui strategi teosentris untuk Al-Quran dan Al-Hadits.Imam al-Ghazali mencirikan tokoh dalam bukunya Ihya 'Ulumuddin adalah sikap (karakter, karakter) yang tetap kokoh dalam jiwa dan jiwa individu adalah sumber pengembangan kegiatan tertentu darinya, tanpa masalahjuga, ringan, tanpa perlu berpikir atau bersiap.(Farida Hasyim, 2019:21)

Dari pengertian karakter, ada dua syarat yang harus dipenuhi, yaitu: kekuatan dan aktivitas yang tidak dibatasi. Ketergantungan menyiratkan bahwa kegiatan tersebut dilakukan oleh seseorang yang langgeng dan dapat dipertahankan. Tentang alam unconstrained menyiratkan bahwa kegiatan tersebut berlangsung secara efektif dan tanpa intimidasi. Kedua kepribadian inilah yang menentukan etika seseorang yang dimilikinya karakter yang dapat diperkirakan atau sebaliknya. Akibatnya, kepribbadian al-Ghazali mengacu pada kondisi otak manusia (shurat al-bathina).(S. I. Shapiro, G. W. L. and P. L. G, 2002:21).

\section{Hakikat Manusia}

Sangat mungkin ditemukan bahwa Alquran dan hadits mendasari semua pelajaran Al-Ghazali. Terlebih lagi, menjadi sumber motivasi yang signifikan, kualitas dan perspektif individu untuk hidup. Dalam terang penting untuk memberikan dasar pada cara pandang Al-Ghozali tentang masyarakat baru-baru ini mengungkap pemahaman al-Qur'an tentang manusia. Kebebasan dasar menurut Al Ghozali seperti dalam al-Qur'an meliputi: Sebuah. Al-Qur'an memberikan ketenangan yang tinggi pada harga diri manusiajulukan "khalifah di bumi".(Shapiro and Denise H. Lajoie, 2018:35)

1. Naluri manusia tidak tercemar dan berbakti

2. Al-Qur'an menyatakan bahwa pada manusia ada jiwa selain raga dan jiwanya. Jiwa itu ada sebelum manusia dikandung, selama dia masih hidup. Ketiga hal ini normal untuk pengalaman Islam tentang manusia yang sejauh ini telah mengenalinya dari 
pengalaman filosofis dan hipotesis karakter yang ada. Khususnya mengenai jiwa yang sampai saat ini masih dirahasiakan. Perspektif dan pelajaran Al-Ghazali sehubungan dengan insting manusia menarik diri dari pemahaman Dia tentang pembentukan manusia seperti yang diungkapkan dalam Al-Qur'an: "Dan kapan Saya menyelesaikan kesempatan manusia saya meniup jiwa saya ke dalam dia. Kesempatan ini menyimpulkan, selain hal-hal lain: Sebuah. Cara untuk mengkonsolidasikan komponen material didapat dari perwujudan kotoran dengan komponen Jiwa yang berasal dari Allah yang terjadi di organisme yang baru jadi telah disiapkan terlebih lagi, kembangkan untuk mendapatkannya. Terlebih lagi, ketika kombinasi ini terjadi, itu terjadi orang lain yang mendalam.(Raudlatul Jannah, 2017:47).

3. Terlepas dari kenyataan bahwa Jiwa manusia berasal dari Allah SWT namun dia bukanlah Tuhan atau pun bagian dari Tuhan, namun secara eksklusif ciptaan-Nya yang diidentifikasikan dengan Tuhan sering disalahartikan sebagai siang hari untuk matahari.

4. Selain itu, karena Jiwa berasal dari wilayah surgawi, khususnya wilayah Malakut dan wilayah Amr, maka pada saat itu juga.

Ide pertama tentang jiwa tidak tercemar dan secara konsisten mencari informasi tentang Tuhan dan jalannya kekekalan sebagai pengaturan untuk kembali kepada-Nya sekali lagi. Dalam ihya ulumuddin, Al-Ghozali mengkaji empat komponen utama desain karakter manusia khususnya hati, jiwa, akal dan nafs.(H.Frie, R, 2017:123).

\section{Dorongan Dan Emosi}

Perasaan menjadi substansi dari keinginan, keinginan dan perasaan manusia untuk dipenuhi setiap kebutuhan; makan, minum, berpakaian, menikah, melindungi diri sendiri, menyangkal resiko, balas dendam. Al-Ghazali mengemukakan 4 kualitas pada manusia; Subuiyyah (makhluk liar), Bahimiyah (makhluk liar), Syaitoniyah (penjahat, iblis), rabbaniyah (Tuhan). Jika perasaan dan sahwat menguasai dirinya, ia akan bertingkah laku seperti makhluk liar, jika ada rabbaniyah di dalam dirinya, ia melihat dirinya memiliki ciri-ciri Kekudusan, jika seseorang benar-benar mengagumi kekuasaan, makna fasisme, rasakan cakap dan berpendidikan meskipun fakta bahwa ia tidak memiliki informasi, keinginan yang tinggi dan begitu seterusnya maka dia 
memiliki gagasan tentang setan. Jika Anda suka pertengkaran dan pembantaian jadi dia punya ide tentang monster.(Saputra, 2018:43)

\section{E. Dinamika Kepribadian Psikologi Islam Menurut Al - Ghozalie}

Kepribadian menurut ilmu psikologi Islam yang dikemukakan oleh imam $\mathrm{Al}$ Ghozalie adalah bergabungnya kerangka hati, akal, dan kepentingan manusia yang membawa perilaku. Sudut nafsanimanusia memiliki tiga kekuatan, khususnya: (1) hati (fitrah ilahiyah) sebagai sudut pandang supra-kesadaran orang yang memiliki kekuatan nafsu (rasa); (2) akal (fitrah insaniah) sebagai bagian dari kesadaran manusia yang memiliki kekuatan intelektual (membuat); (3) keinginan (fitrah hayawaniyah) sebagai bagian dari pra atau kejelasan orang yang memiliki kekuatan konasi (tujuan). Tiga bagian nafsani iniberkoordinasi untuk memahami perilaku.(Raudlatul Jannah, 2017:88).

Hati punya kecenderungan gagasan tentang jiwa, nafs (keinginan dan ghadhab) untuk dimiliki kecenderungan temperamen tubuh, sedangkan jiwa memiliki kecenderungan setengah jalan jiwa dan raga. Menurut perspektif level, karakter itu adalah kombinasi dari bagian supra-kesadaran (fitrah keilahian), kesadaran (naluri manusia), dan pra atau lupa (sifat makhluk). Sedangkan menurut perspektif kapasitasnya, karakter merupakan gabungan dari kekuatan semangat, wawasan dan konasi, yang ditunjukkan dalam tingkah laku luar.(berjalan-jalan, berbicara, dan sebagainya) seperti perilaku internal (renungan, sentimen, dan sebagainya). Karakter benar-benar hasil kolaborasi di antara ketiga bagian itu, hanya ada satu lagi membanjiri dari berbagai bagian. Dalam kerja sama itulah yang dimiliki hati situasi yang berlaku dalam mengendalikan karakter.(Hasanah, 2019:29)

Standar kerja mengawasi naluri manusia, yang sakit akan kehadiran Tuhan dan jiwa yang tak bercacat. Realitas hati umumnya dikendalikan oleh kerangka kontrolnya. Kerangka kendali yang dimaksud adalah dhamir yang berpedoman pada fitrah al munazzalah (Al-Qur'an dan Sunnah). Jika kerangka kontrol ini berfungsi sebagaimana mestinya, pada saat itu karakter manusia sesuai dengan urutannya yang diberikan oleh Tuhan dalam domain kontrak. Padahal, jika kerangka kontrol bekerja maka karakter manusia akan dibatasi oleh segmen lain yang lebih kecil.(Farida Hasyim, 2019:25) Aturan kerja yang masuk akal adalah mencari hal-hal yang masuk akal dan rasional. Dengan cara ini, prinsip menjalankan akal adalah mengikat dan menahan keinginan. 
Pada titik ketika usaha fundamental ini dimurnikan, nalar mampu untuk menyadari sifat bawaannya yang paling penting, betapapun tidak, kecerdasan disalahgunakan oleh nafsu. Sementara energi bekerja sebagaimana mestinya mencari kesenangan umum dan ingin menggambarkan minat sembrono. Ketika pengaturan kendali hati dan jiwa melemah, ada keinginan Siap menyadari sifat intrinsiknya, namun jika itu kerangka kendali jantung lebih jauh lagi, akal terus bekerja, kekuatan keinginan melemahkan. Keinginan itu sendiri daya tarik yang luar biasa kuatnya kontras dengan dua kerangka fitrah nafsani lain. Kekuatan itu dihasilkan oleh bantuan dan gumaman Setan terlebih lagi, aksi tidak hati-hati lainnya. Ide tentang energi mendorong kebencian yang mengerikan. Namun, ketika dia diberikan kebaikan oleh Allah, dia menjadikekuatan positif, menjadi keinginan (iradah) dan kapasitas (qudrah) khusus tingkat serius.(Judy D, 2017:32)

\section{Kepribadian Ammarah (nafsal-ammarah)}

Kepribadian geram adalah karakter yang cenderung karakter substansial dan mencari standar kegembiraan aturan). Kepribadian pemarah menguasai pekerjaan hati melakukan aktivitas sederhana sesuai sifatnya entah, jadi itu adalah tempat dan sumber ofensif dan perilaku keji. Kepribadian yang marah adalah karakter yang terpengaruh mendorong pikiran batin manusia. Pada saat itu pada kenyataannya tidak lagi memiliki kepribadian manusia, dengan alasan bahwa kualitas manusia telah hilang. Manusia itu Karakter yang marah tidak bisa hancur begitu saja, tapi juga bodoh.(Saputra, 2018:49) Realitasnya dikendalikan oleh dua orang kekuatan, khususnya: (1) keinginan yang secara konsisten membutuhkan keinginan, menikmati diri sendiri, perlu mengetahui dan mencampuri masalah orang lain, dll; (2) kekuatan ghadah yang secara konsisten perlu rakus, rakus, menghalangi, berjuang, perlu mengontrol individu, keras kepala, penting diri, sombong, dan seterusnya Jadi arahan karakter kemarahan adalah mengikuti atribut makhluk. Kepribadian yang marah dapat berlanjut ke karakter yang baik jika telah diberi keindahan oleh Allah SWT. Ini penting mempersiapkan atau riyadhah yang luar biasa untuk melumpuhkan kekuatan keinginan di udara, seperti puasa, berdoa, memohon.(Hujib, A, 2018:22)

2. Akhlak Lawwamah (nafsal-lawwamah)

Akhlak lawwamah merupakan akhlak yang diperoleh cahaya hati, pada saat itu dia bangun untuk memperbaiki penundaan di antara keduanya dua hal. Dalam 
pengerahan tenaga, yaitu, beberapa saat demonstrasi berkembang ketidaksetujuan yang dibicarakan oleh sikapnya yang membosankan, bagaimanapun dia diingatkan oleh nurilahi, dengan tujuan agar aktivitas dan aktivitasnya tinggi pada saat itu ia berdamai dan melakukan istighfar. Hal ini dapat dirasakan bahwa karakter lawwamah dipertanyakan sifat kemurkaan dan sifat muthmainnah. Karakter lawwamah adalah karakter yang kewalahan dengan akal. Sebagai bagian yang memiliki naluri manusia, akal ikuti aturan kerja rasionalistik dan masuk akal yang dibawa orang pada tingkat kesadaran.(Shehu, 2013:13) Jika kerangka kontrol berfungsi, pada titik itu akal bisa sampai pada puncaknya seperti mendapatkan logika. Logika telah diciptakan oleh banyak humanis mengatur mentalitasnya menjadi kekuatan "semua" manusia, jadi itu manusia-sentris.(Raudlatul Jannah, 2017:48)

Rasa ketika sudah diberi taburan annur hati, pada titik itu kapasitasnya bisa diterima. Ini cenderung digunakan sebagai tujuan klinis Tuhan. Al-Ghazali sendiri, meski secara khusus menitikberatkan pada metodologi rasa ( $z a w q)$, namun dia benarbenar menggunakan kapasitas akal. Sementara itu, menurut Ibn Sina, akal bisa sampai pada pemahaman teori dan kecerdasan juga diperlengkapi untuk menerima banyak informasi dari Tuhan. Akibat posisi goyah ini, Ibnu Qayyim Al-Jauziyah membagi karakter lawwamah menjadi dua bagian, khususnya: (1) akhlak lawwamah malumah, khususnya akhlak lawwamah yang lalai dan berperilaku buruk; (2) karakter lawwamah ghayrmalumah, khususnya tokoh yang menegur aktivitasnya mengerikan dan berusaha memperbaikinya.(Nurviyanti Cholid, 2018:78)

\section{Sifat Muthmainnah (nafsal-muthmainnah)}

Kepribadian muthmainnah adalah karakter yang telah diberikan kesempurnaan hati nur, dengan tujuan agar dapat meninggalkan ciri-ciri tersebut Bagus. Karakter ini secara konstan ditempatkan pada segmen hati dapatkan kebajikan dan musnahkan seluruh bumi, agar dia diam. Berasal dari karakter Muthmainnah hati manusia, karena hati yang sepi dapat merasakan thuma'ninah. Sebagai bagian dari hati surgawi terus menerus memperhatikan ketenangan dalam cinta, cinta, mohon maaf, lakukan tawakkal, dan carilah ridha Allah SWT. Arah karakter ini teosentris (Surat Al-Nazi'at). Karakter muthmainnah adalah karakter yang bergantung pada atau supra-kesadaran manusia, dengan arah karakter ini adalah teosentris. Dikatakan demikian karena karakter ini terasa pendiam dalam mentolerir keyakinan umum.(Suparlan, 2012:39) Keyakinan 
umum adalah keyakinan yang tertusuk pada jiwa manusia di ranah jiwa dan kemudian disahkan oleh pengungkapan ilahi. Pertemuan ini tidak berkurang secara signifikan enggan seperti yang dialami oleh karakter lawwamah, namun penuh keyakinan. Dengan cara ini, karakter muthmainnah menjadi terbiasa memanfaatkan kekuatan rasa (zawq) dan imajinasi dalam menerima sesuatu, sehingga Karakter muthmainnah merasa yakin dan tenang. Al-Ghazali mengungkapkan bahwa kekuatan hati mengatur kepribadian muthmainnah diperlengkapi untuk pencapaian informasi ma'rifat melalui kekuatan rasa (zaqw) dan perasaan membuka selubung rahasia itu menghalangi pandangan internal manusia. Dengan kekuatan dan Keutamaan kekuatan hati, pada saat itulah orang dapat memperoleh informasi pengungkapan dan motivasi dari Penguasa. Pengungkapan yang diberikan kepada para nabi, moderat motivasi diberikan kepada pria surgawi biasa. Realitas informasi ini suprarasional, sehingga kemungkinan besar dia tidak akan dikenal merasakan. Informasi yang dapat ditangani dengan alasan seharusnya selain itu ditangkap oleh hati, karena hati itu penting untuk kekuatannya digunakan untuk alasan. Namun, terlepas dari apa yang diharapkan secara umum, informasi itu diakui oleh hati tidaklah cukup untuk alasan.(Zilbersheid, 2019:76)

\section{Penutup}

Kepribadian adalah bagian dari roh yang membentuk kehadiran orang menjadi satu kesatuan, tidak terpisah dalam kapasitas. Memahami karakter berarti memahami orang secara total. Sigmund Freud merencanakan ada tiga komponen dalam pembangunannya kepribadian, khususnya citra diri, dan super hati nurani.

kepribadian menurut psikologi islam yang dikemukakan oleh $\mathrm{Al}$ - Ghozalie adalah koordinasi kerangka jantung,alasan, dan kepentingan manusia yang mengarah pada perilaku. Perspektif nafsani manusia memiliki tiga kekuatan, khususnya: (1) hati (fitrah ilahiyah) sebagai perspektif kesadaran supra manusia yang memiliki kekuatan antusias (rasa); (2) akal (fitrah insaniah) sebagai bagian dari kesadaran manusia yang memiliki kekuatan intelektual (membuat); (3) keinginan (fitrah hayawaniyah) sebagai bagian dari pra atau kejelasan orang yang memiliki kekuatan konasi (tujuan).

Ada tiga elemen kepribadian menuru $\mathrm{Al}$ - Ghozalie dalam sudut pandang Islam, tepatnya kepribadian ammarah (nafsal-ammarah), kepribadian lawwamah (nafsal lawwamah), kepribadian muthmainnah (nafsal-muthmainnah). Kepribadian kemarahan 
adalah karakter yang mengawasi kepribadian tubuh dan mencari aturan kegembiraan. Dia menguasai bagian dari hati untuk melakukan perbuatan yang setuju dengan rendah hati dengan indranya yang kasar, jadi dia adalah tempat sekaligus sumber ofensif dan perilaku keji. Karakter lawwamah adalah karakter yang kewalahan oleh akal. Sebagai segmen yang memiliki naluri manusia, nalar mengikuti aturan kerja rasionalistik dan masuk akal yang membawa orang ke tingkat kesadaran. Pada titik ketika kerangka kendali bekerja, akal bisa sampai di puncaknya seperti mendapatkan logika. Banyak sekali logika diatur untuk sikapnya pada kekuatan "semua" orang, jadi manusia-sentris di alam. Karakter muthmainnah adalah karakter itu telah diberi kesempurnaan nur hati, sehingga meninggalkan sifat-sifat yang agung.

\section{DAFTAR PUSTAKA}

Afifudin Alfarisi, Muhamad,(2015), Studi Perbandingan Psikologi Menurut Ibrahim Elfiky Dan Mario Teguh, Junal Teknologi Pendidikan,Vol.2.No.12: 42.

Ali, Y,(2012), Problema Psikologi Manusia Modern dan Solusinya dalam Perpektif Tasawuf, Jurnal Tasawuf:1.

Andriansahroji, (2019), Fenomena Psikologi, gay, biseksual dan transgender (lgbt) di indonesia serta upaya pencegahannya. Jurnal Studi Keislaman:62-74.

Cholid, Nurviyanti, (2018), Konsep Kepribadian Al-Ghozali Untuk Mencapai Hasil Konseling Yang Maksimal, Jurnal Psikologi Islam,Vol.5. no. 1: 55-75.

H.Frie, R,(2017), On The Nature and Meaning of Human Finitude. The American Journal of Psychoanalysis,Vol.6.No.5:123-125.

Hasanah, (2019), Dinamika Kepribadian Menurut Psikologi Islami, Jurnal At-Tarbiyah, Vol.5.No.4:20-23.

Hasanah, Muhimmatul,(2018), Dinamika Kepribadian Menurut Psikologi Islami, Jurnal Ke Islaman, XI, no: 110-122.

Hasyim, Farida, (2019), Upaya Pembentukan Kepribadian Muslim Di SD IT Program Studi Pendidikan Agama Islam Fakultas Tarbiyah Dan Ilmu Keguruan Institut Agama Islam Negeri (IAIN) Purwokerto,Jurnal Pendidikan Islam, Vol.1.No.4: 21.

Hujib, A, (2018), Konsepsi Dasar Kepribadian Islam, Jurnal Tazkiya, Vol.2.No.4:22.

Husna, Faiqatul, (2018), Aliran Psikoanalisis Dalam Perspektif Islam, Jurnal AtTarbiyah Moderen, Vol.5, no. 2: 99-112.

Jannah, Raudlatul, (2017), Upaya Meningkatkan Kepribadian Keberhasilan Pembelajaran Pendidikan Agama Islam, Madrosatuna: Journal of Islamic Elementary School 1, no. 1: 47.

Judy D,(2017),Transpersonal Psychology: Mapping Spiritual Experience, Journal Religions, Vol.2.No.6: 32.

S. I. Shapiro, G. W. L. and P. L. G,(2002), The Essence of Transpersonal Psychology, The International Journal of Transpersonal Studies, Vol.2.No.2: 21.

Saputra, Anri, (2019), Mela Rospita, and Vivik Shofiah, Qalbu Dalam Kajian Psikologi Islam, Jurnal Tazkiyah, Vol.18, no. 1: 37-51. 
Saputra, Rospita, and Shofiah,(2018) Qalbu Dalam Kajian Psikologi Islam, Jurnal Psikologi Post Moderen, Vol.3.No.4:43-46.

Shapiro and Denise H. Lajoie,(2018) Definition of Transpersonal Psychology: The First Twenty Years-Three Years, The Journal of Transpersonal Psychology, Vol.2.No.4:, 35.

Shehu,(2013), Toward an Islamic Perspective of Developmental Psychology. The American Journal of Islamic Social Scienc :15.

Sudjana Aki,(2016), Dalam Membentuk Perkembangan Kepribadian Anak : Perspektif Psikologi Perkembangan Islam, Jurnal Pendidikan Islam,:91-118.

Suparlan, (2012),Dimensi Spiritual dalam Psikologi Modern (Psikologi Transpersonal sebagai Pola Baru Psikologi Spiritual), Jurnal International Conference on Islamic Studies, Vol.3 No.14:33.

Ulfa, Khoiriyah, (2015), Tipologi Manusia dalam Kepribadian Psikologi Islam. TAZKIYA Journal of Psychology, Vol.6 No.9: 123-140.

Walsh, R, \& Vaughan, F,(2020) On Transpersonal Definitions. Journal of Transpersonal Psychology,Vol.5.No.12:22-25.

Zilbersheid, U,(2019) The Historical Character of Human Nature in Freud's Theories. The American Journal of Psychoanalysis, Vol.3.No.2:73. 